\title{
The recurrent plexiform neurofibroma of the scalp in neurofibromatosis type 1: illustrative case
}

\author{
Galih Indra Permana, MD, ${ }^{1}$ M. Arifin Parenrengi, MD, PhD, ${ }^{1}$ Wihasto Suryaningtyas, MD, PhD, ${ }^{1}$ Dyah Fauziah, $M D,{ }^{2}$ and \\ Muhammad Azzam, MD'
}

Departments of ${ }^{1}$ Neurosurgery and ${ }^{2}$ Pathological Anatomy, Universitas Airlangga, Dr. Soetomo General Academic Hospital, Surabaya, East Java, Indonesia

\begin{abstract}
BACKGROUND Plexiform neurofibroma is a benign tumor of the peripheral nerves. It is an unusual variant of neurofibroma originating from all parts of the nerve. Plexiform neurofibroma is primarily pathognomonic and exhibits an unusual variant from neurofibromatosis type 1 (NF1). The possibility of malignancy and recurrence are the main reasons for long-term, close follow-up.

OBSERVATIONS The authors report a case of a 14-year-old girl with a recurrent plexiform neurofibroma derived from the peripheral nerves, which also presented with a typical sign of NF1 disease. The aim of the tumor resection is symptomatic relief.

LESSONS Accomplishing a good outcome can be related to good perioperative planning and a precise operative procedure. The result of anatomical pathology determines the prognosis of the patient. Clinical examination and radiological studies are needed to evaluate the recurrence of complications after surgical procedures.
\end{abstract}

https://thejns.org/doi/abs/10.3171/CASE2024

KEYWORDS plexiform neurofibroma; neurofibromatosis type 1; recurrent; tumor resection

Neurofibroma is a benign tumor of the peripheral nerve sheath. It arises due to the abnormal proliferation of Schwann cells, perineural cells, and endoneurial fibroblasts. Several types of pathology are identified, including localized, plexiform, and diffuse types. ${ }^{1,2}$ Neurofibromatosis type 1 (NF1) is a neurocutaneous, autosomal dominant disorder. ${ }^{3} \mathrm{NF} 1$ affects approximately $1 / 2700$ newborns, with variable presentation and disease severity. ${ }^{3}$ The disease manifestations are café-au-lait macules (CALMs), neurofibromas, skin-folding freckling, iris hamartomas (Lisch's nodules), optic pathway gliomas, and skeletal deformities. ${ }^{1,3}$ Plexiform neurofibroma is a benign tumor of the peripheral nerves (World Health Organization grade I) and an unusual variant of neurofibroma that arises from a proliferation of all parts of the nerve. Plexiform neurofibroma is essentially pathognomonic of NF1. ${ }^{2,4-6}$ This tumor has a significant risk of eventual malignant transformation. ${ }^{7}$ The possibilities of malignancy and recurrence are the main reasons for long-term, close follow-up. ${ }^{8-13}$ Plexiform neurofibromas are an uncommon type of NF1 developed from multiple nerves as bulging and deforming masses that also involve connective tissue and skin folds, also known as "bags of worms."13-17 We report a case of recurrent plexiform neurofibroma, originating from the peripheral nerves, which also presented with typical signs of NF1 disease.

\section{Illustrative Case \\ History and Examination}

A 14-year-old girl presented with a recurrent tumor mass in the posterior scalp, right parietooccipital region. She complained of pain in the tumor region that eased with morphine medication. She had been diagnosed with NF1 at age 10 years based on the clinical signs of numerous CALMs, pseudoarthrosis, cutaneous neurofibroma, and one plexiform neurofibroma. She underwent brain magnetic resonance (MR) imaging examination, which demonstrated a mass in the posterior scalp, right parietooccipital region. There was T2 signal abnormality extending in the right parietooccipital region with increased signal intensity. There was no abnormality in the brain and along the optic nerve. We distinguished healthy tissues and tumors by the different hair colors. The tumor region had more white hair color than black hair color, as in healthy tissues (Fig. 1). At 6 years of age, she had undergone orthopedic surgery procedures for pseudoarthrosis in the right tibia.

ABBREVIATIONS CALM = café-au-lait macule; MR = magnetic resonance; NF1 = neurofibromatosis type 1.

INCLUDE WHEN CITING Published January 11, 2021; DOI: 10.3171/CASE2024.

SUBMITTED September 20, 2020. ACCEPTED October 14, 2020.

(C) 2021 The authors, CC BY-NC-ND 4.0 (http://creativecommons.org/licenses/by-nc-nd/4.0/), 

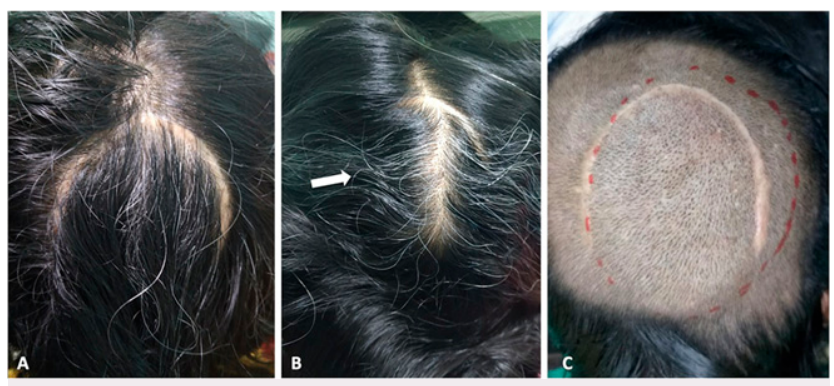

FIG. 1. A 14-year-old girl patient presented with a recurrent soft tissue mass (dotted line) in the parietooccipital region after resection had been performed $(\mathbf{C})$. We could differentiate healthy tissues and tumors by the difference in the hair colors ( $\mathbf{A}$ and $\mathbf{B})$. Tumor areas were revealed by whiter hair color (arrow) than healthy tissues.

She had undergone surgery for neurofibroma in the right parietooccipital region at age 10 years. The anatomical pathology result was plexiform neurofibroma. She routinely came to the clinic for clinical evaluation. Four years later, she presented with a recurrent tumor mass and pain. The tumor measured approximately $9 \times 11 \times 2 \mathrm{~cm}$ and was solitary, mobile, and not attached to the bone below it. She also had another mass in the lower back, approximately $5 \times 3 \times 2 \mathrm{~cm}$, solitary, mobile, and not attached to its muscle. She had CALMs all over the body with a maximum diameter of more than $15 \mathrm{~mm}$ (Fig. 2). The patient also presented with tibial pseudoarthrosis, and surgery was performed for the orthopedic procedure.

MR imaging evaluation showed that the lesion had reappeared in the same location four years after the initial surgical procedure (Fig. 3).

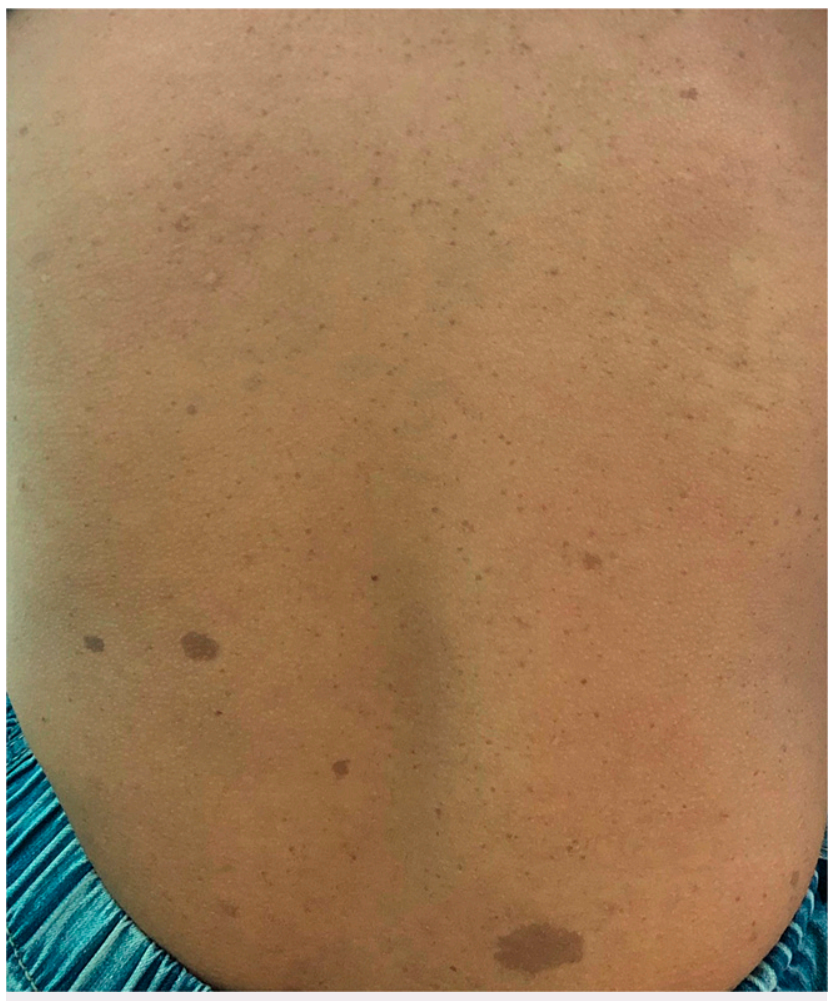

FIG. 2. Patient presented with CALMs in the back region with a variation of diameters.
MR imaging demonstrated contrast enhancement of the subcutaneous soft tissue mass in the parietooccipital region. The mass was smaller than before with the same imaging intensity on MR imaging. Management options were discussed with the family, including tumor resection with a preserved epidermis layer above the tumor or aggressive tumor resection with a skin flap. The family agreed to a tumor resection with preservation of the epidermis layer above the tumor, considering the risks of the skin flap, such as alopecia in the flap region because of the patient's age and gender.

\section{Pathological Examination}

The tumor grossly appeared as a mass with white-gray color and rubbery, dense consistency. The intraoperative cytological preparation showed cells with a mixture of fat tissue and tumor cells between them. Tumor cells consist of proliferative cells with an oval nucleus and partly wavy spindle, smooth chromatin, and elongated cytoplasm. The stroma contains collagen fibers. There was no sign of malignancy or tumor cells infiltration to the epidermis layer (Fig. 4). The pathological studies led to the diagnosis of the plexiform neurofibroma, which was the same as previous results. It was a recurrent tumor without any sign of malignancy.

\section{Operation and Postoperative Course}

Resection of the tumor lesion was performed under general anesthesia (Fig. 5). During the operation, the tumor was noted to be highly infiltrative into its epidermis layer. The resection was done by carefully separating the cutaneous and subcutaneous layers. The tumors were located in the subcutaneous layer. It is important to know the border of healthy tissues and tumors. Total resection of the tumor up to the margin of healthy tissue was gently performed. The target of the resection was up to where the hair follicles of the epidermis layer were seen. The patient was evaluated by routine clinical examination in the clinic and MR imaging 3 months postoperatively.

\section{Discussion}

NF1 is a condition of rare autosomal dominant genetic mutations of the NF1 gene at chromosome 17q11.2. ${ }^{1}$ Clinical manifestations of this abnormality consist of multiple skin alterations such as CALMs and axillary freckling, and by tumoral growth along nerves, called "neurofibromas." "1,5,18-21 Plexiform neurofibroma is an unusual type of neurofibroma and a benign tumor of the peripheral nerve that possesses a high risk of malignant transformation. $7,13,16,18,19,22-25$ Plexiform neurofibromas are usually diagnosed in early childhood and found in approximately $30 \%$ of NF1 cases, most frequently in the craniomaxillofacial region. ${ }^{7,13,26}$ Malignant transformation occurs in $2 \%$ to $16 \%$ of cases and is considered the leading cause of mortality. ${ }^{27} \mathrm{NF} 1$ is diagnosed using 2 or more criteria from the National Institutes of Health. Plexiform neurofibromas are diagnosed clinically by the typical manifestations of the disease. Histopathological studies are performed to differentiate malignant changes. ${ }^{3,4,11,12,15,17,20,28-30}$ Our patient had the manifestations of numerous CALMs, pseudoarthrosis, cutaneous neurofibroma, and one plexiform neurofibroma. Surgery remains the treatment of choice in plexiform neurofibromas. Total resection of the tumor mass is performed when malignant transformation occurs, especially in recurrent cases. The incidence of recurrence is $20 \%$ of cases, even when the approach was done appropriately. ${ }^{31,32}$ Given this concern and its nature, some authors ${ }^{23,33}$ suggest that neurofibroma should receive a more radical tumor mass resection. Even this tumor recurrence may occur even if completely resected. The tumor resection aims to relieve the symptoms. $22,23,31,34-36$ This patient had undergone total resection of the tumor. Four years later, the patient presented with 

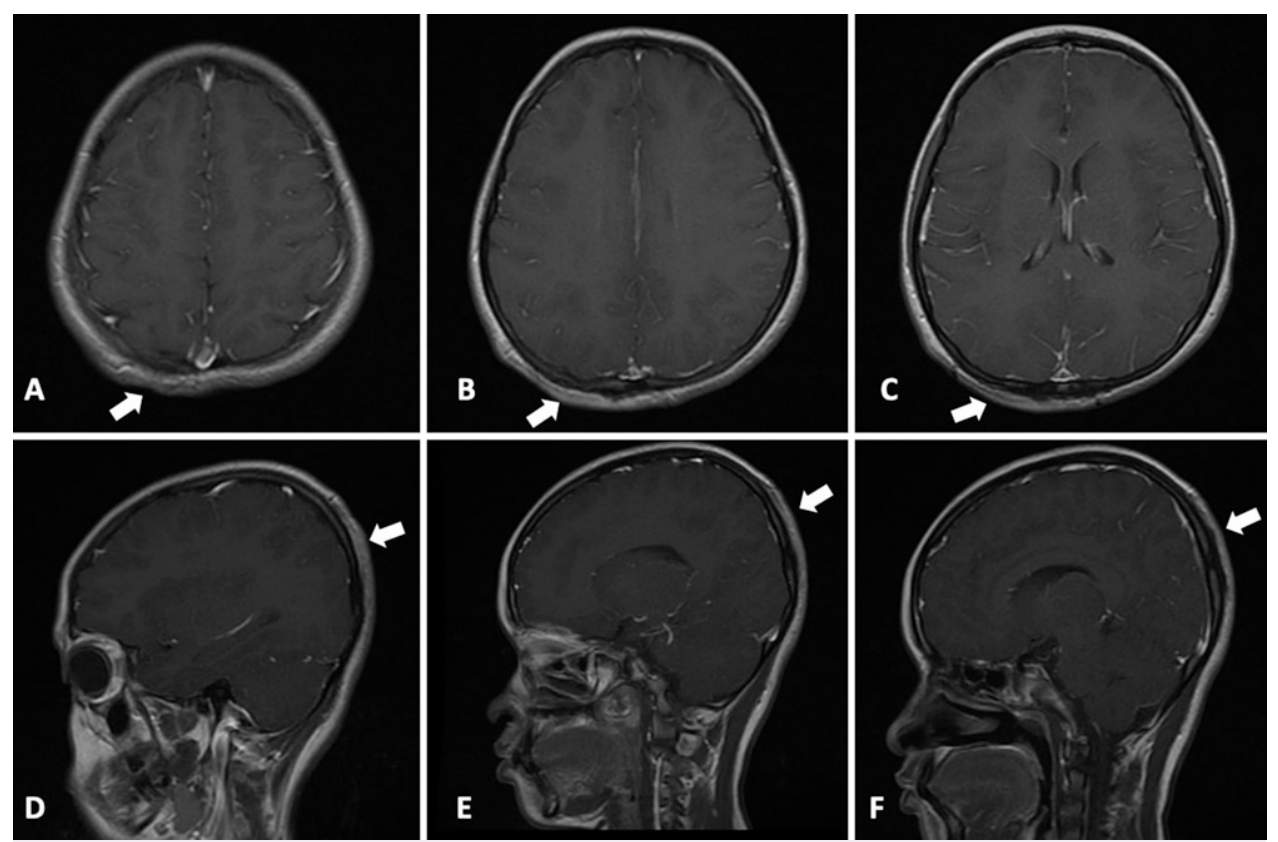

FIG. 3. MR imaging, axial (A-C) and sagittal (D-F) sections, demonstrated contrast enhancement of subcutaneous soft tissues (arrows) in the right parietooccipital region, 4 years after tumor resection.

a recurrent tumor in the same location as previously and a pain that did not subside with nonopioid medication.

\section{Observations}

A more aggressive surgery should be performed, especially in the case of recurring symptoms. Surgical tumor mass resection indications in neurofibroma include pain, functional impairment, cosmetics, and malignant transformation. . $^{273,37-39}$ The procedure should have realistic aims, and the associated risks should be explained to patients and families. We explained the surgical technique and the surgery's goal to the patient and her family, including whether we would perform aggressive tumor resection to the cutaneous epidermis layers above the tumor or tumor resection with preservation of the cutaneous layers above the tumor. Aggressive resection had the advantages of minimal risk of recurrence and relief of the symptoms. However, we needed to perform a massive surgical flap, which is a complicated surgical procedure and may cause alopecia in the affected skin. ${ }^{31,33,34,37,40,41}$ This surgical approach optimally recovers the appearance and function of the patient. However, neurofibroma usually has diffuse tissue infiltration, which barely allows complete total resection. ${ }^{18,33,41,42-44}$ Tumor resection with preservation means patients can still take care of the cosmetics in the affected skin, but the risk of recurrence is more significant than with the other procedure. This approach depends on how aggressive the resection is and how carefully the healthy tissue is preserved. Total tumor resection up to the margin of healthy tissue is challenging to perform due to extensive involvement with adjacent

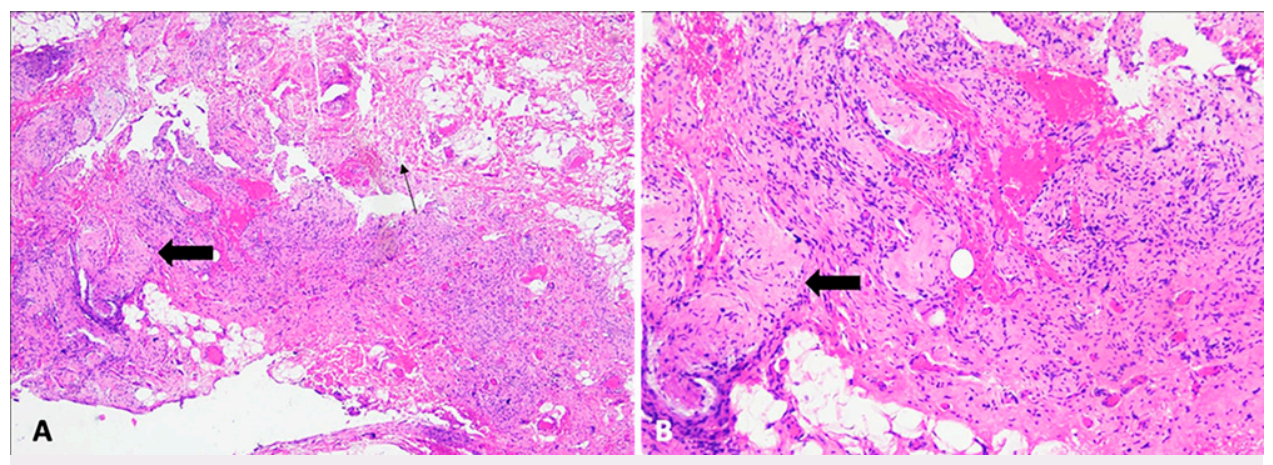

FIG. 4. Pathological anatomy of the plexiform growth pattern showing multiple tumoral nodules, each composed of loose spindle cells with short, elongated, wavy nuclei embedded in a mucinous stroma. ${ }^{13}$ There is no cutaneous infiltration of the tumor (arrows). Hematoxylin-eosin stain, original magnifications $\times 40(\mathbf{A})$ and $\times 100(\mathbf{B})$. 

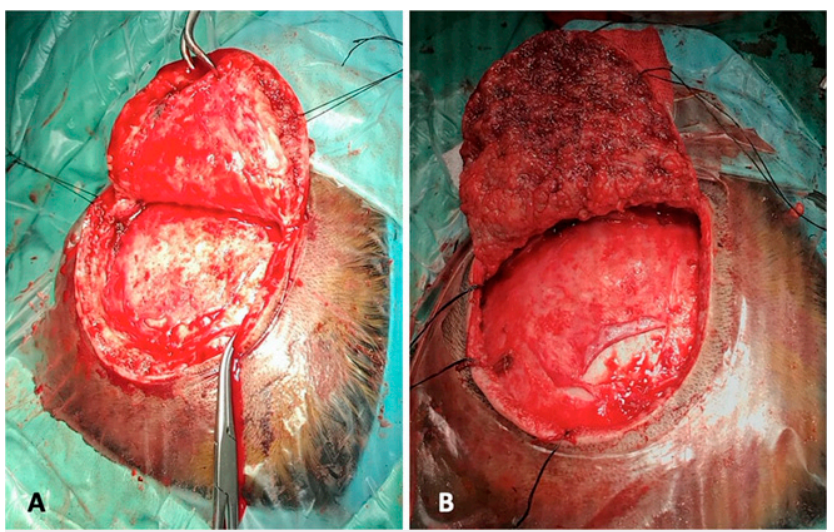

FIG. 5. Aggressive tumor resection with preservation of epidermis layers. Soft tissue mass tumor before tumor resection (A). After tumor resection revealed the hair follicles that showed the healthy tissue (B).

tissues. In our case, we performed aggressive tumor resection with preservation of the epidermis layer up to the healthy tissue border. A pathological study showed no sign of malignancy or tumor cell infiltration to the epidermis cutaneous layer. After the procedure, clinical and radiological evaluations were scheduled to seek another recurrence risk.

\section{Lessons}

Plexiform neurofibromas exhibit an unusual type of NF1 with a higher risk of recurrence after surgical procedure. Recurring tumor harbors a high risk for malignant transformation. Accomplishing a good outcome can be related to good perioperative planning and precise operative procedure, without local recurrence complications. Periodic clinical and radiology imaging examinations are essential in the evaluation of the recurrence.

\section{Acknowledgments}

We acknowledge the support from Department of Pathological Anatomy, Dr. Soetomo General Academic Hospital, in preparing microscopic views of tumor anatomical pathology.

\section{References}

1. Albright AL, Pollack IF, Adelson PD. Principles and Practice of Pediatric Neurosurgery. 3rd ed. New York, NY: Thieme publishers; 2015.

2. Tonsgard JH. Clinical manifestations and management of neurofibromatosis type 1. Semin Pediatr Neurol. 2006;13(1):2-7.

3. Jallo GI, Kothbauer KF, Recinos VMR. Handbook of Pediatric Neurosurgery. New York, NY: Thieme publishers; 2018.

4. Krohel GB, Rosenberg PN, Wright JE, et al. Localized orbital neurofibromas. Am J Ophthalmol. 1985;100(3):458-464.

5. Ardashev VN, Seriakov AP, Nikolaeva SN, et al. Diagnostics of neurofibromatosis (Recklinghausen disease). Article in Russian. Voen Med Zh. 2004;325(6):41-44.

6. Ferner RE, Huson SM, Thomas N, et al. Guidelines for the diagnosis and management of individuals with neurofibromatosis 1. J Med Genet. 2007;44(2):81-88.

7. Prada CE, Rangwala FA, Martin LJ, et al. Pediatric plexiform neurofibromas: impact on morbidity and mortality in neurofibromatosis type 1. J Pediatr. 2012;160(3):461-467.
8. Raja Al, Yeaney GA, Jakacki RI, et al. Extraventricular neurocytoma in neurofibromatosis type 1: case report. J Neurosurg Pediatr. 2008;2(1):63-67.

9. Yohay K. Neurofibromatosis type 1 and associated malignancies. Curr Neurol Neurosci Rep. 2009;9(3):247-253.

10. Matrix H, Origin U, Laffan EE, et al. Pediatric soft-tissue tumors and pseudotumors: MR imaging features with pathologic correlation. Radiographics. 2009;36:1-35.

11. Weiss LM. Soft Tissues. 2nd ed. Elsevier Inc.; 2009.

12. Jett K, Friedman JM. Clinical and genetic aspects of neurofibromatosis 1. Genet Med. 2010;12(1):1-11.

13. Abbas $O$, Bhawan J. Cutaneous plexiform lesions. J Cutan Pathol. 2010;37(6):613-623.

14. Onesti MG, Carella S, Spinelli G, et al. A study of 17 patients affected with plexiform neurofibromas in upper and lower extremities: comparison between different surgical techniques. Acta Chir Plast. 2009;51(2):35-40.

15. Brosius S. A history of von Recklinghausen's NF1. J Hist Neurosci. 2010;19(4):333-348.

16. Listernick R, Gutmann DH. Neurofibromatosis. Vol 1. 2nd ed. Elsevier Inc.; 2010.

17. Rafik A, Diouri M, Bahechar N, et al. Unusual evolution of plexiform neurofibroma in the scalp: a case report. World J Plast Surg. 2018;7(1):128-131.

18. Khajavi M, Khoshsirat $S$, Ahangarnazari $L$, et al. A brief report of plexiform neurofibroma. Curr Probl Cancer. 2018;42(2):256-260.

19. Tchernev G, Chokoeva AA, Patterson JW, et al. Plexiform neurofibroma: a case report. Medicine (Baltimore). 2016;95(6): e2663.

20. Williams VC, Lucas J, Babcock MA, et al. Neurofibromatosis type 1 revisited. Pediatrics. 2009;123(1):124-133.

21. Gross AM, Singh G, Akshintala S, et al. Association of plexiform neurofibroma volume changes and development of clinical morbidities in neurofibromatosis 1. Neuro Oncol. 2018;20(12): 1643-1651.

22. Bakshi SS. Plexiform neurofibroma. Cleve Clin J Med. 2016; 83(11):792.

23. Polak M, Polak G, Brocheriou C, et al. Solitary neurofibroma of the mandible: case report and review of the literature. J Oral Maxillofac Surg. 1989;47(1):65-68.

24. Evans DG, Howard E, Giblin C, et al. Birth incidence and prevalence of tumor-prone syndromes: estimates from a UK family genetic register service. Am J Med Genet A. 2010;152A(2): 327-332.

25. Liu S, Zhou X, Song A, et al. Giant plexiform neurofibroma of thigh in a young woman. Postgrad Med J. 2019;95(1126):459-460.

26. Ruggieri M, Pavone V, Polizzi A, et al. Unusual form of recurrent giant cell granuloma of the mandible and lower extremities in a patient with neurofibromatosis type 1. Oral Surg Oral Med Oral Pathol Oral Radiol Endod. 1999;87(1):67-72.

27. Sabatini $C$, Milani D, Menni F, et al. Treatment of neurofibromatosis type 1. Curr Treat Options Neurol. 2015;17(6):355.

28. Kumar S, Bhaskar S, Handa A, et al. Diffuse neurofibroma of scalp. Asian J Neurosurg. 2014;9(4):237.

29. Smith KB, Wang DL, Plotkin SR, et al. Appearance concerns among women with neurofibromatosis: examining sexual/bodily and social self-consciousness. Psychooncology. 2013;22(12): $2711-2719$

30. Riccardi VM. Von Recklinghausen neurofibromatosis. N Engl J Med. 1981;305(27):1617-1627.

31. Friedrich RE, Schmelzle R, Hartmann M, et al. Resection of small plexiform neurofibromas in neurofibromatosis type 1 children. World J Surg Oncol. 2005;3(1):6.

32. Needle MN, Cnaan A, Dattilo J, et al. Prognostic signs in the surgical management of plexiform neurofibroma: the Children's 
Hospital of Philadelphia experience, 1974-1994. J Pediatr. 1997; 131(5):678-682.

33. Balaji SM. Surgical management of recurrent neurofibroma of infratemporal region: a case report with 20-year follow-up. Indian J Dent Res. 2017;28(6):695-698.

34. Roberts AHN, Crockett DJ. An operation for the treatment of cutaneous neurofibromatosis. Br J Plast Surg. 1985;38(2):292-293.

35. Parsons CM, Canter RJ, Khatri VP. Surgical management of neurofibromatosis. Surg Oncol Clin N Am. 2009;18(1):175-196, x.

36. Slam KD, Bohman SL, Sharma R, et al. Surgical considerations for the familial cancer syndrome, neurofibromatosis 1: a comprehensive review. Am Surg. 2009;75(2):120-128.

37. Kim HJ, Lee KG, Yi SM, et al. Successful treatment of multiple cutaneous neurofibromas using a combination of shave excision and laser photothermocoagulation with a 1,444-nm neodymiumdoped yttrium aluminum garnet laser. Dermatologic Surg. 2012; 38(6):960-963.

38. Chiang YZ, Al-Niaimi F, Ferguson J, et al. Carbon dioxide laser treatment of cutaneous neurofibromas. Dermatol Ther (Heidelb). 2012;2(1):7.

39. Lutterodt CG, Mohan A, Kirkpatrick N. The use of electrodessication in the treatment of cutaneous neurofibromatosis: $A$ retrospective patient satisfaction outcome assessment. J Plast Reconstr Aesthet Surg. 2016;69(6):765-769.

40. Uygur F, Chang DW, Crosby MA, et al. Free flap reconstruction of extensive defects following resection of large neurofibromatosis. Ann Plast Surg. 2011;67(4):376-381.

41. Levine SM, Levine E, Taub PJ, et al. Electrosurgical excision technique for the treatment of multiple cutaneous lesions in neurofibromatosis type I. J Plast Reconstr Aesthet Surg. 2008;61(8):958-962.

42. Wolkenstein P, Durand-Zaleski I, Moreno JC, et al. Cost evaluation of the medical management of neurofibromatosis 1 : a prospective study on 201 patients. Br J Dermatol. 2000;142(6): $1166-1170$.

43. Babovic-Vuksanovic D, Widemann BC, Dombi E, et al. Phase I trial of pirfenidone in children with neurofibromatosis 1 and plexiform neurofibromas. Pediatr Neurol. 2007;36(5):293-300.

44. Kriechbaumer LK, Susani M, Kircher SG, etal. Comparative study of CO2- and Er:YAG laser ablation of multiple cutaneous neurofibromas in von Recklinghausen's disease. Lasers Med Sci. 2014;29(3):1083-1091.

\section{Disclosures}

The authors report no conflict of interest concerning the materials or methods used in this study or the findings specified in this paper.

\section{Author Contributions}

Conception and design: Permana, Parenrengi, Suryaningtyas. Acquisition of data: Permana, Parenrengi. Analysis and interpretation of data: Permana, Parenrengi, Suryaningtyas. Drafting the article: Permana, Parenrengi, Suryaningtyas. Critically revising the article: Parenrengi, Fauziah. Reviewed submitted version of manuscript: Parenrengi, Suryaningtyas, Fauziah. Approved the final version of the manuscript on behalf of all authors: Permana. Statistical analysis: Parenrengi. Administrative/technical/material support: Permana, Parenrengi. Study supervision: Parenrengi. Assisted corresponding author: Azzam.

\section{Correspondence}

Galih Indra Permana: Airlangga University, Dr. Soetomo General Academic Hospital, Surabaya, East Java, Indonesia. md.galih@ gmail.com. 